\title{
Gênero, corpo e sexualidade nos livros para a infância
}

\section{Gender, body and sexuality in childhood books}

\author{
Constantina Xavier Filha ${ }^{1}$
}

\begin{abstract}
RESUMO
Livros para a infância sobre gênero, sexualidade e diversidade são fontes inesgotáveis e férteis para estudos. De 2006 a 2013, serviram de fontes a três pesquisas sob minha coordenação, a partir do referencial teórico dos estudos culturais, dos estudos de gênero e dos pressupostos foucaultianos. Os livros foram analisados como dispositivos pedagógicos para a educação da infância. Foram analisados em relação à linguagem adotada, suas possibilidades de produzir subjetividades na infância bem como por aquilo que produzem e veiculam sobre corpo, gênero e sexualidade. Dentre os dados das pesquisas a destacarmos merece ser enfatizada, nas últimas décadas, a grande profusão de livros dirigidos ao público infantil, sobretudo a partir de 1980. Muitos deles são escritos por autores/as brasileiros/as, o que parece ser um aspecto positivo, pois, nas décadas anteriores, o que havia era uma quantidade considerável de livros traduzidos, que, obviamente, refletiam outras realidades. O que não se vê, no entanto, é a participação efetiva das crianças nessas obras, além de serem silenciadas algumas temáticas como a violência contra a criança e a homossexualidade. O presente artigo tem por objetivo fazer um balanço dos estudos realizados, buscando entender essa produção como artefato cultural e como dispositivo pedagógico de educação da infância, afora salientar algumas características que expressam como eles podem ser instrumentos educativos para as crianças.
\end{abstract}

Palavras-chave: livros para a infância; dispositivo pedagógico; subjetividade; pesquisa com crianças.

DOI: $10.1590 / 0104-4060.36546$

1 Universidade Federal de Mato Grosso do Sul. Departamento de Educação. Campo Grande, Mato Grosso do Sul, Brasil. Cidade Universitária s/n - Universitário. Caixa Postal: 549. CEP: 79070-900. 


\begin{abstract}
Childhood books on gender, sexuality and diversity are inexhaustible and fertile sources for studies. From 2006 to 2013 they constituted sources of three researches under my supervision, developed from the theoretical framework of cultural studies, gender studies and Foucauldian presuppositions. The books were analyzed as pedagogical devices for children's education. They were discussed concerning the language adopted, their possibilities of producing subjectivities during childhood, as well as concerning what they produce and convey about body, gender and sexuality. Among the data that is worthy to be highlighted over the last decades is the great amount of books directed to children, particularly since the 1980s. Many of them were written by Brazilian authors and this seems to be a positive fact since in earlier decades there was a considerable amount of translated books, which obviously reflected other cultural realities. What has not been noticed, however, is the effective participation of children in these works, in addition to the silencing of some issues such as violence against children and homosexuality. This article seeks to propose a balance of those studies, trying to understand this production as a cultural artifact and as a pedagogical device to the education of children, besides emphasizing some features that express how they can be educational tools for children.
\end{abstract}

Keywords: childhood books; pedagogical device; subjectivity; research with children.

\title{
Os "livros para a infância" como artefatos culturais
}

As questões de gênero, corpo, sexualidade, diferença e diversidade, nas últimas décadas, vêm ganhando espaço nas publicações para a infância, especialmente em livros. Essas publicações constituíram fontes das minhas pesquisas desde 2006 até os dias atuais ${ }^{2}$. Os referenciais teóricos adotados nessas pesquisas foram os estudos de gênero, os estudos culturais e as teorizações foucaultianas. Assim, pretendo, neste artigo, descrever e discutir algumas características desses livros. Na primeira parte do texto, busco conceituá-los e entendê-los como artefatos culturais e instrumentos de dispositivos pedagógicos para a educação da infância; na segunda, realizo um balanço das três últimas pesquisas realizadas, destacando alguns resultados, apontando as principais temáticas tratadas, do CNPq.

2 As pesquisas desenvolvidas e coordenadas por mim contaram com apoio da Fundect e 
além de abordar também o silêncio sobre uma série de questões ausentes nos livros. Pretendo ainda analisar algumas características que os identificam como dispositivos pedagógicos para a educação da infância.

Os livros com as temáticas de gênero e sexualidade tornaram-se objetos e fontes das minhas pesquisas a partir do ano de 1999, período em que iniciei o primeiro estudo com 18 livros infantis, disponíveis para venda na cidade de Campo Grande, capital do estado do Mato Grosso do Sul (XAVIER FILHA, 2001). Na época, o estudo foi impulsionado por uma constante procura de alunas do curso de Pedagogia, que solicitavam listas e indicações de livros para serem trabalhados com as crianças, em especial aqueles que privilegiassem temas considerados "delicados". Naquele período, ensaiei, junto com duas alunas do curso de Pedagogia, uma experiência de pesquisa com crianças, visando à construção coletiva de um livro infantil. Entretanto, essa tentativa não obteve êxito. Apesar da falta de sucesso, persistiu o desejo de estudar os livros infantis e de escrever um livro dirigido para e com as crianças. Era comum que as educadoras supusessem a existência de um "livro ideal" a ser indicado para o/a filho/a, tanto para ser lido privadamente como também para ser usado na prática pedagógica. Também faziam questionamentos sobre as obras e sobre a relação com a faixa etária das crianças. Essas e outras questões me levaram a realizar um primeiro estudo, fazendo dos livros para a infância potentes objetos e fontes de análise.

Por que os livros para a infância podem ser tomados como fontes e/ou objetos de pesquisa? Quais elementos presentes nesses livros podem justificar as análises, os questionamentos e as reflexões? Quais temas e por que razão são silenciados ou privilegiados?

Tais perguntas impulsionaram as investigações que destacam o potencial educativo desses livros, tomados aqui como importantes artefatos culturais produzidos para a infância. A maioria dos/as autores/as compartilha da ideia de que esses artefatos culturais e sociais educam ao expressar "formas de ser" masculino ou feminino, entre outros elementos que constituem identidades (FELIPE, 1998; FURLANI, 2005; XAVIER FILHA, 2001, 2009d, 2012b).

Os artefatos culturais produzem significados, ensinam determinadas condutas às meninas e aos meninos e estabelecem a forma "adequada" e "normal" de viver a sexualidade, a feminilidade ou a masculinidade. Giroux e McLaren (1995) ressaltam que há pedagogia em qualquer lugar em que se produz conhecimento. Assim, os vários contextos educacionais da sociedade bem como os mais diferentes artefatos culturais, como cinema, mídia, revistas, livros, brinquedos, entre outros, expressam e fazem circular discursos que produzem as subjetividades. Entender os livros como artefatos culturais que expressam pedagogias é uma tarefa que nos leva a analisar os próprios textos e ilustrações 
para, contudo, questionar conceitos e também promover a reflexão e a autorreflexão dos leitores e leitoras.

Os livros que abordam as temáticas de gênero, sexualidade, diversidade/ diferença são tomados em minhas pesquisas como artefatos culturais e elementos dos dispositivos pedagógicos para a educação da infância. No âmbito das pesquisas realizadas, venho denominando tais livros como "livros para a infância”. Entretanto, não há consenso sobre a denominação mais apropriada. Pelo contrário, há acirradas discussões a esse respeito. Há quem os chame de "paradidáticos" e também quem os considere como livros "didáticos". O que parece importante salientar nessa questão é seu caráter pedagógico/didático em relação aos demais livros que, "supostamente", não seguiriam tal orientação. Porém, para que um livro possa ser considerado "paradidático", é necessário que ele apresente conteúdos curriculares específicos, tal como ocorre na maior parte do mercado de livros comerciais e escolares. Por exemplo, em conteúdos didáticos da área curricular de Ciências, há livros paradidáticos sobre o descarte do lixo, sobre as doenças sexualmente transmissíveis, entre outros temas. Utilizando esse exemplo, os livros sobre sexualidade poderiam ser considerados paradidáticos para "complementar" ou aprofundar os conteúdos transversais de orientação sexual (BRASIL, 1997). Nesse caso, alguns livros poderiam ser considerados paradidáticos. Ao que parece, nessa denominação, isto é, como paradidáticos, eles teriam um alcance propriamente pedagógico e escolar. Entretanto, isso não foi observado na maioria dos livros analisados nas pesquisas, especialmente aqueles publicados mais recentemente. Isto é, os livros publicados nos últimos anos apresentam características que extrapolam o aspecto didático ou suplementar dos conteúdos curriculares, até mesmo porque é sabido que o tema transversal de orientação sexual nem sempre é trabalhado nas escolas, especialmente com crianças pequenas.

Outra discussão importante sobre os livros para a infância diz respeito ao seu caráter literário, isto é, se podem ser considerados literatura. Silveira, ao analisar a temática da "diferença" no âmbito da literatura infantil, alerta sobre "uma preocupação mais pragmática com a formação da criança para 'conhecer' e aceitar o diferente [...], ensejando uma proliferação de títulos dentro de várias vertentes da temática" (2003, p. 2). Para a autora, essa questão acalenta acirradas discussões acadêmicas ligadas à crítica da literatura infantojuvenil sobre o estatuto artístico-literário e não pedagógico desse tipo de produção. Nesse sentido, há um grupo de pesquisadores/as que defende a separação entre literatura, isto é, livros desprovidos de pretensões educativas imediatas, e outros livros categorizados como didáticos, paradidáticos, que possuem o objetivo explícito de educar sobre 
determinados temas. Essa suposta divisão é fruto da construção histórica que permitiu legitimar a categoria específica da literatura infantojuvenil:

\begin{abstract}
Ainda que a chamada renovação da literatura infantojuvenil das últimas décadas tenha se colocado sob a égide do abandono do padrão pedagógico explícito, padrão que se manifestava abertamente em lições de moral e em um maniqueísmo de caracteres, por exemplo, é evidente que as "novas" obras, como quaisquer produtos culturais, também são produzidas dentro de contextos, valores, quadros de referência e verdades em que seus autores e autoras se situam, os quais podem ser (ou não) partilhados por pais, mães, professores/as, psicólogos, ativistas de movimentos sociais em favor de determinadas minorias, representantes das próprias minorias, etc. (SILVEIRA, 2003, p. 3).
\end{abstract}

Nos livros analisados por Silveira, assim como naqueles estudados nas nossas pesquisas, é evidente a presença de uma preocupação com a função pedagógica da obra. No entanto, é possível afirmar que mesmo os livros destinados à infância que tratam de outras temáticas e que são considerados como literatura infantil, mesmo na ausência de objetivos educativos explícitos sobre determinados assuntos, isto é, aqueles tomados como obras artísticas, também educam. É a partir desse pressuposto que os estudos culturais nos possibilitam entender os livros como artefatos culturais. Independentemente de serem considerados literatura, todos educam, de alguma forma. Eles expressam modos de ser menina ou menino e produzem no leitor ou leitora maneiras de ser no mundo, de pensar, de construir problemas, de confrontar-se com a realidade e consigo mesmo/a, tudo em um tipo de relação específica estabelecida com a leitura.

Assim, os "livros para a infância" que venho analisando como artefatos culturais e pedagógicos constituem dispositivos pedagógicos para educar a infância, e o conceito de dispositivo pedagógico é aqui pensado a partir das noções de dispositivo e de subjetivação de Michel Foucault. Questionamentos sobre as práticas do sujeito para consigo mesmo foram abordados por Foucault na última fase de sua obra, na primeira metade dos anos de 1980. Ao recuperar elementos de uma entrevista concedida em 1984, Foucault ressaltou que o objeto de suas investigações se centrava no encontro entre o sujeito e a produção da verdade. Afirmava, na oportunidade, que aquilo que é tomado como verdade pode assumir a forma de ciência, de modelo científico ou de enunciados que, nas instituições, se traduzem em práticas de controle. Para ele, as relações estabelecidas entre o sujeito e os jogos de verdade podem obedecer a práticas coercitivas, a jogos 
teóricos, ou científicos, e também a práticas de si. Os indivíduos tornam-se sujeitos de diversas maneiras: por meio de jogos que estabelecem em relação às práticas coercitivas de instituições (como a família, a escola, dentre outras), na relação com os jogos teóricos, que produzem "práticas divisoras" a partir de discursos que normalizam condutas, e, finalmente, pelo trabalho do próprio sujeito sobre si mesmo (FOUCAULT, 1995). O indivíduo não é passivo diante das forças externas a ele. Ele é, sobretudo, ativo, pois é capaz de produzir jogos de verdade consigo mesmo para se constituir como sujeito, já que dispõe de mecanismos com os quais atua sobre si mesmo e que o ajudam a se constituir. O processo de subjetivação, entretanto, se faz de forma "intersubjetiva, através dos outros e em relação com eles (incluindo o próprio eu)" (DEACON; PARKER, 2000, p. 101).

Outro importante conceito utilizado para analisar os livros como instrumentos de educação da infância é aquilo que Larrosa considera como "dispositivo pedagógico". Segundo o autor, o "dispositivo pedagógico" é "qualquer lugar no qual se aprende ou se modifica ou se transforma a experiência de si. Qualquer lugar no qual se aprendem ou se modificam as relações que o sujeito estabelece consigo mesmo" (2000, p. 57).

$\mathrm{O}$ autor analisa as diferentes dimensões que constituem o "dispositivo pedagógico" para a produção e mediação da experiência de si. São elas: a dimensão óptica (o que é visível dentro do sujeito para si mesmo), a dimensão discursiva (o que o sujeito pode e deve dizer acerca de si mesmo), a dimensão jurídica (o sujeito deve julgar a si mesmo segundo uma trama de normas e valores), a dimensão narrativa (construção discursiva e temporal da experiência de si) e a dimensão prática (o que o sujeito pode e deve fazer consigo mesmo).

Os livros infantis publicados entre 1930 e 1970 revelam características comuns em relação à adoção de uma linguagem impositiva e normativa a respeito da sexualidade da criança. A partir da década de 1970, há mudanças em relação às temáticas com vistas a uma aproximação do texto e das ilustrações com o possível público leitor. Nas últimas décadas, porém, as mudanças ocorrem com a inclusão de uma linguagem mais lúdica, que traz aspectos estéticos e conteúdos que visam à reflexão e à discussão de temas ligados às dúvidas e aos problemas vivenciados pelas crianças. Tais estratégias captam os/as leitores/as produzindo neles/as a identificação do reconhecimento dos saberes instituídos pelos livros, o que os/as leva à autoanálise e à autocondução diante daqueles saberes-poderes-verdades expressos pelos livros. Tais aspectos constituem importantes elementos dos vários dispositivos pedagógicos utilizados contemporaneamente para educar a infância. O livro é um deles e, dada a sua importância cultural, merece destaque nas pesquisas. Um primeiro destaque leva em consideração que ele educa ao mesmo tempo adultos e crianças. O livro é comprado pelas pessoas 
adultas, que também o escolhem. Escolhido e comprado, transforma-se em um instrumento que educa adultos e crianças, indicando e apresentando as maneiras consideradas por eles como adequadas de viver a sexualidade.

Depois de ter tomado o livro como instrumento dos dispositivos pedagógicos para a educação da infância, passo à descrição de algumas características encontradas que servirão para ilustrar, exemplificar e discutir vários aspectos importantes.

\section{Livros para a infância como fontes de pesquisa: o que eles têm a nos dizer?}

Alguns anos após a conclusão da primeira pesquisa sobre livros para a infância (2001), voltei a analisar essas fontes, em 2006. Agora, não só os livros direcionados às crianças e aos adolescentes, mas também ao público adulto. A pesquisa teve como título "Já é tempo de saber...": a construção discursiva da educação sexual em manuais e em livros infantojuvenis - 1930 a 1985 do século XX (2006-2009). O resultado final deu origem à elaboração do Catálogo digital de bibliografias sobre sexualidade, educação sexual e gênero - 1930 a 1985. Esse catálogo apresenta os dados coletados e analisados, além de se constituir em um banco de dados destinado às pessoas interessadas em estudar a temática tendo os livros como fontes.

Nesse trabalho, foi identificado e coletado um total de 361 livros, dentre eles alguns denominados manuais, destinados ao público adulto. Os demais eram direcionados para a infância e para a adolescência. Todos tinham por temáticas a sexualidade e o gênero. Um dos critérios para a seleção das fontes foi possuírem a característica de conter orientações relativas à sexualidade na infância e na adolescência/juventude, além de indicativos sobre esse tipo de educação, apoiando-se nas ciências biológicas, médicas, psicológicas, pedagógicas e religiosas. A linguagem impositiva, normativa e prescritiva constituiu um dos elementos fundamentais que fazem dos manuais e livros infantojuvenis instrumentos privilegiados de dispositivos pedagógicos. A criança, especialmente, é tomada como objeto de conhecimento, passando a ser esquadrinhada, medida, estudada, hierarquizada e homogeneizada. Esse procedimento estabelece divisões e atribui rótulos, fabricando-se a criança "normal". A educação da sexualidade e de gênero também tem por objetivo orientar a conduta das pessoas adultas diante das expressões de sexualidade de crianças e de adolescentes/jovens, além de definir as condutas idealizadas para que meninos e meninas se constituam. 
Os livros foram agrupados segundo as tipologias direcionadas para cada público-alvo: enciclopédias infantojuvenis (indicadas para adultos ou para crianças e jovens) e manuais (livros em geral e os de puericultura, indicados para o público adulto). Desse montante, os manuais configuraram como maioria. Os livros infantojuvenis encontraram-se em número reduzido, sendo apenas 50 (XAVIER FILHA, 2009b).

Das produções coletadas no estudo, destaca-se o paulatino aumento das publicações destinadas ao público infantojuvenil. Apesar de esses livros não constituírem a maioria, eles registraram um aumento de publicação, especialmente a partir da década de 1970 e, sobretudo, na de 1980. Os livros infantojuvenis com a temática da educação sexual também se apresentaram como "manuais" para que a própria criança, ou o/a adolescente/jovem, pudesse realizar uma autoanálise e assumir condutas consideradas "normais" ou "corretas" para a construção de sua identidade, dentre elas a sexual e a de gênero. Eis aqui outro elemento que estabelece a teia dos dispositivos pedagógicos desses artefatos culturais.

Em continuidade com esse estudo, dei prosseguimento a outra pesquisa focando somente os livros para a infância e ampliando o arco histórico de 1930 até 2010. A pesquisa intitulada Gênero e sexualidade em livros infantis: análises e produção de material educativo para/com crianças (2008-2012), com apoio do CNPq, seguiu dois eixos teórico-metodológicos: a) pesquisa bibliográfica: que teve por fontes livros para a infância com os temas sexualidade, gênero e diversidade. Ao final do processo de investigação, foi produzida uma coletânea $(C D-R O M)$ das fichas dos livros analisados com a intenção de socializar as fontes para pesquisas posteriores; b) pesquisa com crianças: realizada em escola pública, propunha discutir com o público infantil os livros produzidos para esse segmento, além da construção coletiva de materiais educativos, dentre eles um filme de animação e um livro para a infância, contando com a efetiva participação das crianças.

Os resultados dessas últimas duas pesquisas demonstraram que, a partir da segunda metade do século XX e sobretudo a partir da década de 1980, houve um aumento editorial significativo de livros com a temática da pesquisa para o público infantil. Também é importante ressaltar que, nas últimas décadas, os livros publicados no Brasil ganharam mais espaço em relação aos traduzidos de línguas estrangeiras. Os livros apresentam os temas de diversas formas, a depender do período histórico em que foram publicados e a partir do referencial teórico e moral de cada época. No entanto, na maioria deles, há elementos independentes desses fatores, como a heterossexualidade, que ainda se configuram como a única e desejável possibilidade de constituição da identidade sexual. A 
homossexualidade aparece nos livros escritos na década de 2000 especialmente quando a temática é a diversidade familiar.

Outro assunto recorrente é a construção do corpo feminino ligado à procriação. O corpo reprodutivo é ainda representado como um dado "natural" desejável e esperado para as meninas, aspecto observado nas duas pesquisas citadas. $\mathrm{O}$ corpo, em alguns livros, é enfatizado nos termos biológicos da reprodução. A sexualidade, mesmo nos livros mais recentes, é, em sua maioria, quase sempre desvinculada do prazer. Os corpos masculino e feminino são fragmentados, com ênfase no aspecto biológico e em sua constituição física como sinônimos de beleza, isto é, são apresentados como corpos jovens, magros e brancos.

Os livros das décadas da primeira metade do século XX trazem conceitos ora da religião, ora da medicina e ora de moralidade da época. Alguns ressaltam todos esses temas conjuntamente. Outro aspecto a destacar na análise dos livros é a apresentação de duas perspectivas de infância. Uma assexuada, que necessita aprender para conduzir sua sexualidade, e outra, de uma infância sexuada, que necessita ser educada para não ser um problema no futuro.

Os dados aqui expressos apresentam aspectos importantes a serem problematizados. Os livros para a infância demonstram conceitos em seus textos e ilustrações que indicam aquilo que é considerado como "normal" para a vivência da sexualidade nesse período da vida. Predomina uma linguagem impositiva e normativa que visa dizer aquilo que é considerado "correto" na educação das crianças. Todos esses aspectos compõem o que venho considerando como elementos dos dispositivos pedagógicos para a educação da infância. Os livros educam, instigam o próprio sujeito leitor a se questionar e a se gerir. Em alguns casos, a controlar-se a partir daquilo que se considera ser a sexualidade "normal" e desejável.

Alguns livros, publicados mais recentemente, tentam discutir esses enunciados e propõem novas formas de socializar informações, a saber, sair do meramente pedagógico para indicar possibilidades de diálogo, de ludicidade, de criatividade, de imaginação e de reflexão. A criança é vista majoritariamente como sexuada e como alguém que questiona a vida, questiona tudo, inclusive sua sexualidade. Assim, os temas relacionados ao gênero passam a ser pensados e debatidos. Meninas ocupam lugares de destaque e de comando. Os meninos passam a experienciar a possibilidade de serem frágeis e de poderem chorar. As famílias homoafetivas passam a ter visibilidade juntamente com os outros arranjos familiares. No entanto, nesses livros, a homossexualidade ainda é pouco presente. Outros temas, como violência sexual e autoerotismo na infância, também continuam pouco expressivos.

A análise dos livros, em todas as pesquisas realizadas, possibilita-nos apresentar algumas características e elementos comuns presentes na maioria deles. 
Esses aspectos também foram evidenciados em outro estudo (FELIPE, 1998), com fontes análogas àquelas da minha pesquisa (XAVIER FILHA, 2001). Dentre essas características, encontramos: a) muitos dos livros utilizam a prerrogativa da infantilização para explicar a prática sexual e a concepção (vê-se o uso de "carinhas" em óvulos e em espermatozoides ou observa-se o emprego de uma linguagem no diminutivo, com o intuito de estabelecer uma aproximação com a "linguagem da infância"); b) há nos discursos uma tendência a explicar a sexualidade com argumentos biológicos, essencialistas e universalistas (quase sempre é excluída a relação de sexualidade com o prazer); c) o corpo, especialmente o feminino, é reduzido à dimensão reprodutora (a constituição do corpo da criança está em linha com sua função reprodutora na idade adulta no âmbito do casamento heterossexual e monogâmico); d) existe uma preocupação em utilizar elementos da natureza para explicar fatos da concepção de crianças, explorando-se amplamente as semelhanças entre animais e humanos; e) o modelo de família mais frequente é o patriarcal e nuclear, composto de membros definidos - pai, mãe e filhos/as; f) alguns temas são praticamente excluídos da maioria dos livros - autoerotismo; homossexualidade, diversidade sexual e violência sexual; g) grande parte dos livros traz informações e conceitos distantes da realidade da criança (observa-se também que há uma desqualificação da capacidade da criança de produzir conhecimentos e de realizar hipóteses e teorias); h) o gênero masculino tem obtido uma visibilidade ativa e dominante (nas imagens, observam-se meninos em situação de atividade e as meninas, em condições de execução de trabalhos domésticos e manuais); i) o essencialismo em relação à identidade de gênero é visto em situações que expressam relação direta entre passividade e submissão por parte do gênero feminino, como nos seguintes exemplos - denominação dos órgãos genitais femininos (geralmente com o uso de palavras no diminutivo); submissão feminina, ao mostrar imagens da relação sexual em que o homem ocupa uma posição superior à da mulher; as imagens que apresentam o momento do parto (as gravuras mais comuns a esse respeito representam mulheres felizes e serenas, o que pode levar a pensar aspectos como os da reprodução aliados à resignação e à idealização da "mulher-mãe"); j) há indicativos de que a procriação feminina seja um dado "natural" desejável e esperado pelas meninas/mulheres; k) a heterossexualidade configura-se como a única e desejável possibilidade de constituição de identidade sexual; 1) o corpo feminino e o corpo masculino, em muitos livros, são fragmentados, ora com ênfase no aspecto biológico, ora com ênfase na construção de ideais do que seja considerado ser belo - corpos jovens, magros, brancos; e, por fim, m) muitos livros trabalham com duas perspectivas - com a concepção de que a infância seja um período assexuado e com a ideia de que a infância, caso seja sexuada, necessite ser educada para não vir a se tornar um problema no futuro. 
Na última pesquisa citada (XAVIER FILHA, 2012b), observamos a existência de livros, publicados na última década, que apresentam novas narrativas em relação às anteriormente salientadas. Há novas ideias, formas diferentes de questionar e de provocar a reflexão no público leitor, novas temáticas, além de uma clara intenção de desestabilizar as verdades consideradas e produzidas como "únicas". Mesmo nesses casos, urge salientar que os livros exercem suas funções como instrumentos de dispositivos pedagógicos na educação da infância. Agora, a infância é pensada com novas possibilidades argumentativas, com seres pensantes, sujeitos produtores de cultura e sujeitos de direitos.

No ano de 2013, terminamos a tríade dos estudos com a última pesquisa, intitulada Representações de violência dentro e fora da escola nas vozes de crianças, também com o apoio do CNPq (2012-2013). Nessa pesquisa, utilizamos os livros coletados e selecionados dos outros estudos, além de selecionar novos livros, com o foco nos temas da violência contra a criança e dos direitos da criança. Alguns desses livros foram lidos e discutidos em encontros com as próprias crianças. Por meio dessa abordagem, produzimos coletivamente três ${ }^{3}$ livros, observando especificamente questões de gênero e de violência contra crianças. Sobre o primeiro assunto - questões de gênero -, percebemos haver vários livros que seguiam uma linha biológica para explicar a diferença entre meninos e meninas; outros, especialmente os mais recentes, buscavam problematizar os estereótipos, os "papéis" de gênero e a produção cultural dos gêneros, apontando para a construção social das diferenças entre meninos e meninas. Destaco dois autores que podem ser representativos e ilustrativos a respeito dessa perspectiva apresentada.

Thierry Lenain (2004), com a personagem Ceci, que desfaz a separação entre os universos dos gêneros. Ceci é a personagem principal do livro Ceci tem pipi? (LENAIN, 2004). A menina, ao chegar à escola, abala as convicções do menino Max, que antes tinha a ideia de que o mundo era separado entre os "com pipi” e as "sem pipi”. O pessoal "com pipi” era mais forte, e essa percepção era uma certeza existente desde que o mundo é mundo, ele acreditava. A menina, em vez de desenhar "florzinha fofinha", escolhe um "mamute enorme", adora jogar futebol, tem bicicleta "de garoto", não tem medo de subir em árvores e, nas lutas, sempre vence. O menino fica cada vez mais intrigado com as atitudes daquela garota. Acredita que ela estava trapaceando, pois "Ceci é uma menina que tem pipi! Uma sem-pipi com pipi...” (LENAIN, 2004, p. 17), questiona o menino. A partir daí, passa a investigar a menina para poder desmascará-la. Ao final, descobre que ela era uma menina sem pipi e chega à conclusão de que

3 Ao longo desses últimos anos, além dos três últimos livros citados, publiquei ao todo sete livros. Cf.: XAVIER FILHA, 2009a, 2009c, 2012a, 2014a, 2014b, 2014c, 2014 d. 
"antes, havia o pessoal com-pipi e o pessoal sem-pipi. Agora, tem os com-pipi e as com-perereca. Pois é... Não tem nada faltando nas meninas!" (LENAIN, 2004, p. 29).

Ainda a respeito das questões de gênero, cito como exemplo Babette Cole. Um dos seus livros é A princesa sabichona (2004), que apresenta como protagonista uma princesa que não queria se casar, pelo contrário, gostava de ser solteira. Ela era cortejada por muitos príncipes, no entanto, queria viver sossegada no castelo, fazendo o que bem entendesse. O rei e a rainha, inconformados com sua decisão, resolvem dar-lhe um ultimato para arranjar um marido. Ela concorda desde que o pretendente passasse em provas que ela determinaria. $\mathrm{E}$ assim acontece! Testes e mais testes, imagináveis e inimagináveis, que colocam à "prova" o ideal de masculinidade de cada pretendente. Para sua surpresa, aparece um príncipe Fanfarrão que consegue cumprir com êxito todos os desafios. Então, ao final, ela resolve dar-lhe um beijo mágico. E ele vira um enorme sapo. Rapidamente, vai embora do castelo. A notícia espalha-se por todo o reino e ninguém mais quer se casar com a princesa Sabichona, assim, "ela vive feliz para sempre".

Esses dois livros apresentam novas formas de discutir a constituição de gênero masculino e feminino. Por gênero, entendemos:

A construção social feita sobre diferenças sexuais. Gênero refere-se, portanto, ao modo como as chamadas "diferenças sexuais" são representadas ou valorizadas; refere-se àquilo que se diz ou se pensa sobre tais diferenças, no âmbito de uma dada sociedade, num determinado grupo, em determinado contexto (LOURO, 2000, p. 26).

Louro destaca que é na sociedade e na cultura que as diferenças biológicas entre homens e mulheres ganham sentido e são representadas. Com efeito, tornamo-nos homens e mulheres na cultura. É disso que os dois livros tratam, utilizando uma linguagem lúdica e imaginativa. Para Louro, o conceito de gênero não possui uma "essência" masculina ou feminina; pelo contrário, aprendemos a ser um e outro e, a partir de então, vamos construindo o gênero com o qual nos identificamos. Essa perspectiva nos leva a pensar que podemos ser masculinos e femininos de diferentes formas, independentemente da norma social e cultural, e isso é apresentado e instigado pelos livros, especialmente pelos dois citados.

Butler (1999) também questiona a construção binária do sexo e do gênero, criticando a separação conceitual de sexo como construção biológica e gênero como construção cultural. Para a autora, gênero não é totalmente cultural, tal 
como o sexo não é natureza. O gênero é igualmente o sentido discursivo/cultural através do qual a "natureza" do sexo, ou o "sexo natural", se fabrica e se fixa como premissa. A crítica de Butler se dirige a uma ideia de construção do gênero que possui a cultura como destino. A desconstrução proposta por Butler passa pelo entendimento de gênero como função discursiva tanto do corpo como da própria cultura.

O conceito de gênero, a partir de autoras e autores pós-estruturalistas, incita a discussão da desconstrução das dicotomias masculino/feminino, privado/público, natureza/cultura, entre outras. Isso significa "problematizar a constituição de cada polo; demonstrar que cada um, na verdade, supõe e contém o outro; evidenciar que cada polo não é uno, mas plural" (LOURO, 2000, p. 16). Nesse sentido, o polo masculino contém o feminino e vice-versa e cada um desses é fragmentado porque representa uma diversidade de sentidos, ou seja, "não existe a mulher, mas várias e diferentes mulheres que não são idênticas entre si, que podem ou não ser solidárias, cúmplices ou opositoras" (LOURO, 2000, p. 16). A oposição também é algo socialmente construído, portanto, não é algo inerente, natural ou fixo.

Com relação ao segundo eixo temático da última pesquisa empreendida - a violência contra a criança -, ainda há poucos livros dedicados a esse tema, em particular quando a violência é sexual. Um dos poucos livros publicados nos últimos anos foi escrito pela autora brasileira Odívia Barros, intitulado Segredo segredíssimo (2011). O livro narra a história de Alice, uma menina de seis anos de idade, que tem uma amiga da mesma idade chamada Adriana. A sua amiga lhe conta um segredo: seu tio queria brincar de "brincadeira de adulto" com ela. Alice incentiva Adriana a contar o ocorrido à sua mãe. Depois disso, o "tio" sai de casa e o final feliz reina ao término do livro. Muito há de se falar do conteúdo da obra e sobre o tema em questão, mas os limites deste artigo não oferecem espaço para aprofundamentos. Aquilo que merece destaque é a emergência dessas temáticas nos últimos anos em livros para a infância. Percebe-se que novas questões e preocupações aparecem nos livros de acordo com as "urgências históricas", mais prementes em determinada época e em resposta a determinados problemas, variando de acordo com a cultura e a sociedade. Um exemplo sobre isso diz respeito aos livros com temáticas sobre a aids, que tiveram o ápice de publicação nas décadas de 1980 até 1990. Depois disso, não mais encontramos textos para crianças sobre esse assunto. Esse é mais um elemento da grande rede que compõe os dispositivos pedagógicos da educação das infâncias, ou seja, esses dispositivos estão atrelados ao que se pensa sobre a infância, como se pensa sobre o que seja a infância, o que pode ser considerado o "estatuto" dessa infância, os problemas emergentes de cada período histórico, entre outras questões que constituem essa fase da vida. Os livros são instrumentos, entre 
tantos outros, produzidos social e culturalmente, que expressam indicativos que fazem parte de teorias, conceitos, pressupostos teóricos e científicos, discursos científicos, religiosos, psicológicos, etc., que remetem a várias instâncias que educam as crianças. Por todos esses motivos, sua análise é importante, devendo também ser observados como fontes e/ou objetos de estudos e de pesquisas.

\section{Considerações finais}

Aquilo que se pretendeu enfatizar nos estudos apresentados, tomando os livros para a infância como fontes de investigação, foi produzir um conjunto de reflexões sobre a organização dos enunciados e da linguagem (escrita e ilustrada) encontrados nos textos e ilustrações dos livros das pesquisas do período entre 1930 e 2013. Esses livros visaram orientar as condutas de adultos diante das perguntas de crianças e de adolescentes a respeito da sexualidade e, sobretudo, objetivaram uma autoeducação da criança. A linguagem utilizada, na maioria dos casos, especialmente nos livros publicados nas primeiras décadas das pesquisas, assemelha-se a um receituário que trata das formas de atuar diante das "inoportunas" perguntas das crianças ou diante dos comportamentos desejáveis ou indesejáveis em relação à sexualidade. Esses elementos, entre outros apontados ao longo do texto, constituem o substrato do dispositivo pedagógico que os livros para a infância desenvolvem na educação das crianças. As questões relacionadas ao corpo sexuado de meninas e de meninos e à sua educação de gênero aparecem como temas fundamentais para a educação, sobretudo com a ênfase na heterossexualidade como norma única e desejável. Os livros analisados pretendem produzir uma infância "normal", propondo um desenvolvimento infantil a partir de determinantes biológicos, médicos, psicológicos, sociais e, principalmente, morais. Os enunciados de normalidade pretendem legitimar um discurso de saber-poder com base naquilo que se considera a "verdade", acima de tudo na educação de crianças.

Com relação aos livros para a infância, eles também instigam a reflexão da criança a partir daquilo que "se" considera correto para a sexualidade e para o gênero nesse período da vida. Observamos que pouquíssimos livros têm a participação efetiva das crianças em seus textos e ilustrações, ao contrário, possuem linguagens e preceitos adultos, fazendo com que a obra se mantenha sob a tutela dos discursos adultos. Por essa razão, nas últimas duas pesquisas, apresentamos alguns desses livros às crianças, para que elas pudessem os ler e os discutir. Concomitantemente, produzimos textos, cenários, roteiros e narrativas 
para a escrita de outros artefatos culturais, envolvendo a participação coletiva e dialógica de crianças e de adultos. Nesse processo, criamos, coletivamente, três livros para a infância (XAVIER FILHA, 2014a, 2014b, 2014d), com a finalidade de discutir temáticas como corpo, gênero e violências contra crianças. Especialmente com esses três livros, buscamos destacar a possibilidade de a própria criança ir atrás de ajuda e desenvolver a capacidade de se proteger e de se cuidar em caso de violação de seus direitos.

Essa produção coletiva de livro para/com crianças, empreendida nos últimos estudos, nos fez repensar algumas convicções, justamente por desestabilizar nossas verdades. Questionando e aprendendo com as crianças, construindo espaços para a escrita de livros, de ideias, de novas verdades e de possibilidades colaborativas, a visão "centrada" dos livros escritos por adultos "cai por terra", nessa perspectiva colaborativa da construção coletiva dos textos, cenários, personagens e histórias. Apesar disso, esses livros não são, só por isso, melhores ou piores que muitos outros selecionados e analisados nas pesquisas. Todos fazem parte dessa grande teia dos dispositivos pedagógicos de educação da infância. No entanto, percebo que podemos pensá-los de outras formas, para além daqueles livros que sempre impõem normas e condutas, dizendo o que é certo ou errado. Os livros podem também provocar outros meios de diálogo com o público leitor e instigar novas formas imaginativas de produção de subjetividades - ser menina e ser menino, brincar de novos jeitos e vivências e produzir práticas de liberdade. Nesse sentido, é possível notar os grandes desafios presentes nas redes de possibilidades de saber-poder-resistir.

\section{REFERÊNCIAS}

BARROS, Odívia. Segredo segredíssimo. São Paulo: Geração Editorial, 2011.

BRASIL. Ministério da Educação e do Desporto. Secretaria de Educação Fundamental. Parâmetros curriculares nacionais: pluralidade cultural, orientação sexual. Brasília: MEC/SEF, 1997.

BUTLER, Judith. Gender trouble: feminism and the subversion of identity. London: Routledge, 1999.

COLE, Babette. A princesa sabichona. São Paulo: Martins Fontes, 2004.

DEACON, Roger; PARKER, Ben. Educação como sujeição e como recusa. In: SILVA, Tomaz Tadeu da (Org.). O sujeito da educação: estudos foucaultianos. Petrópolis: Vozes, 2000. p. $97-110$. 
FELIPE, Jane. Sexualidade nos livros infantis: relações de gênero e outras implicações. In: MEYER, Dagmar Elisabeth Estermann (Org.). Saúde e sexualidade na escola. Porto Alegre: Mediação, 1998. p. 111-124.

FOUCAULT, Michel. O sujeito e o poder. In: DREYFUS, Hubert Lederer; RABINOW, Paul. Michel Foucault: uma trajetória filosófica. Para além do estruturalismo e da hermenêutica. Rio de Janeiro: Forense Universitária, 1995.

. História da sexualidade: a vontade de saber. 12. ed. Rio de Janeiro: Graal, 1997. (v. 1).

. A ética do cuidado de si como prática da liberdade. In: Ética, sexualidade, política. Rio de Janeiro: Forense Universitária, 2004. p. 264-287. (Ditos e Escritos, v. 5).

FURLANI, Jimena. O bicho vai pegar: um olhar pós-estruturalista à educação sexual a partir dos livros paradidáticos infantis. Rio Grande: FURG, 2005.

GIROUX, Henry A.; MCLAREN, Peter L. Por uma pedagogia crítica da representação. In: SILVA, Tomaz Tadeu da; MOREIRA, Antônio Flávio (Orgs.). Territórios contestados: o currículo e os novos mapas políticos e culturais. Petrópolis: Vozes, 1995.

LARROSA, Jorge. Tecnologias do eu e educação. In: SILVA, Tomaz Tadeu da (Org.). O sujeito da educação: estudos foucaultianos. 4. ed. Petrópolis: Vozes, 2000. p. 35-86.

LENAIN, Thierry. Ceci tem pipi? Tradução de: JAHN, Heloisa. Ilustrações: Delphine Durand. São Paulo: Companhia das Letrinhas, 2004.

LOURO, Guacira Lopes. Gênero, sexualidade e educação: uma perspectiva pós-estruturalista. Petrópolis: Vozes, 1997.

. Currículo, gênero e sexualidade. Lisboa: Porto, 2000.

SILVA, Tomaz Tadeu da. A produção social da identidade e da diferença. In:

(Org.). Identidade e diferença: a perspectiva dos estudos culturais. 2. ed. Petrópolis: Vozes, 2003.

SILVEIRA, Rosa Maria Hessel. Nas tramas da literatura infantil: olhares sobre personagens "diferentes". Trabalho apresentado no 2. Seminário Internacional de Educação Intercultural, gênero e movimentos sociais, Florianópolis, 2003.

XAVIER FILHA, Constantina. A sexualidade nos livros infantis: a mediação no processo de educação sexual. Campo Grande: UFMS/DED, 2001. Relatório final de pesquisa.

. A menina e o menino que brincavam de ser. Campo Grande: UFMS, 2009a.

. (Org.). Catálogo digital de bibliografias sobre sexualidade, educação sexual e gênero - 1930 a 1985. Campo Grande: UFMS, 2009b. 1 CD-ROM.

. Entre explosões e cortes na barriga: as curiosidades de Rafael. Entre sementes e cegonhas: as curiosidades de Gabriela. Campo Grande: UFMS, 2009c. 
. "Já é tempo de saber...": a construção discursiva da educação sexual em manuais e em livros infantojuvenis - 1930 a 1985 do século XX. Campo Grande: UFMS/ Fundect, 2009d. Relatório final de pesquisa.

. (Org.). Kit de materiais educativos para a educação para a sexualidade, para a equidade de gênero e para a diversidade sexual. Campo Grande: UFMS, 2009e. . As aventuras da Princesa Pantaneira. Campo Grande: Life, 2012a.

. Gênero e sexualidade em livros infantis: análises e produção de material educativo para/com crianças (2008-2012). Campo Grande: UFMS/PROPP/CNPq, 2012 b. Relatório final de pesquisa.

. Representações de violência dentro e fora da escola nas vozes de crianças.

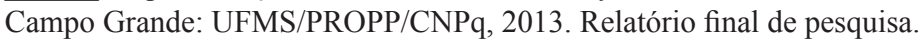
. Do meu corpo eu cuido e protejo. Campo Grande: UFMS, 2014a. . Meninas e meninos têm direitos. Campo Grande: UFMS, 2014b. . Princesa Pantaneira em: brincando no mundo mágico do cinema. Campo Grande: UFMS, 2014c. .Viver sem violência é um direito. Campo Grande: UFMS, 2014d.

Texto recebido em 19 de maio de 2014. Texto aprovado em 20 de maio de 2014. 